\title{
Grouting Reinforcement Mechanism and Multimodel Simulation Analysis of Longwall Goaf
}

\author{
Xueliang Li $\mathbb{D},{ }^{1,2}$ Xiaoli Guo, ${ }^{2,3}$ and Guang Sun ${ }^{1}$ \\ ${ }^{1}$ China Coal Science and Technology Ecological Environment Technology Co., Ltd., Beijing 100013, China \\ ${ }^{2}$ China Coal Research Institute, Beijing 100013, China \\ ${ }^{3}$ CCTEG Beijing Research Institute of Land Renovation and Ecological Restoration Technology Co., Ltd., Beijing 100013, China
}

Correspondence should be addressed to Xueliang Li; cls9350@163.com

Received 31 March 2021; Accepted 5 May 2021; Published 24 May 2021

Academic Editor: Zhengyang Song

Copyright (C) 2021 Xueliang Li et al. This is an open access article distributed under the Creative Commons Attribution License, which permits unrestricted use, distribution, and reproduction in any medium, provided the original work is properly cited.

Grouting reinforcement is one of the most effective methods to enhance the stability of the goaf, and its scheme selection, hole location, and parameter determination directly affect the success or failure of goaf treatment. On the basis of discussion of the deformation mechanism and evolution law of the longwall goaf, this article comprehensively analyzed the grouting reinforcement mechanism of the goaf combined with filling theory, permeability theory, and fracturing theory and studied the physical and chemical reaction principles of two commonly used filling materials, cement-fly ash slurry and cement-clay slurry. Three grouting models have been established: whole grouting, local grouting in fracture zone, and strip grouting, and then simulated the grouting effect of the two more common methods of whole grouting and strip grouting by numerical simulation software (FLAC3D, tecplot, Surfer). Simulation analysis is carried out from the perspectives of settlement deformation, horizontal movement, vertical stress, and horizontal stress. Finally, the feasibility of grouting treatment in the goaf is verified by engineering example. The results show that a reasonable grouting scheme can effectively reduce the residual deformation of the goaf and its overlying rock and improve the poor stress state, so as to achieve the purpose of effective grouting.

\section{Introduction}

In recent years, construction land has gradually become a scarce resource in mining cities and their surrounding areas with the continuous acceleration of urbanization; sometimes, the land above the goaf has to be used to meet construction needs. However, the risk of secondary activation exists in the goaf because of its complex structure and susceptibility to groundwater, earthquake, external loads, and other factors; its stability degree directly restricts the size, volume, and safety of the proposed building [1-3]. In order to ensure safety, appropriate treatment measures must be taken as needed under the premise of scientific demonstration. At present, direct grouting in the goaf is one of the more widely used methods.

The grouting technology in developed industrial countries such as Britain, France, and America started relatively early, and the theoretical research and engineering practice have never stopped. The grouting technology has a wide range of applications in these countries. It has expanded from simple foundation reinforcement and water plugging penetration in mines to hydraulic engineering, bridge and airport construction, and other fields. On the basis of the existing results, scholars have further applied grouting technology in the field of coal mine goaf management. Based on the analysis of the mechanism of residual settlement in the old goaf and the theory of mining subsidence, Deng et al. [4] studied the technical method of grouting and filling to control residual settlement in the old goaf. Xuan et al. [5] proposed a technical scheme for grouting and filling of old goafs to control dynamic disasters under huge thick igneous rocks and achieved good results. Pang et al. [6] explored a new way of alkali slag utilization for the grouting material of an alkali slag-fly ash system filled in the goaf. Wang et al. [7] established Bingham fluid constitutive model equations and performed a three-dimensional Bingham fluid turbulence simulation in the goaf of the South-to-North Water Transfer Project. In order to solve the problem that the goaf along the railway seriously threatens the safety of railway transportation, Li et al. [8] 
carried out the experimental research on different grouting material ratios and determined the reasonable grouting material and slurry ratio. Lu et al. [9] established the relationship between the residual movement angle, the mining depth, and the equivalent mining thickness of the old goaf and proposed the determination method of the filling and grouting range in the old goaf. Yongliang et al. [10] carried out effective detection and evaluation of the grouting effect of a large and complex goaf combined with examples of goaf grouting engineering.

The grouting technology in the goaf is a concealed project, but there is no mature theoretical basis and technical support in the scientific community. Researchers still lack deep understanding of the mechanism of interaction between the grout and fractured rock mass in the goaf, the characteristics of grout migration, and the effect of grouting reinforcement. Based on the mechanism analysis, this study analyzed the grouting effect of different grouting models by means of numerical simulation.

\section{Deformation Mechanism and Evolution Law of Longwall Goaf}

2.1. Geological Mining Model of Goaf. The existing goafs are mainly those left by longwall collapse mining in China, and the existing mining methods of major production mines are also mainly longwall mining. After longwall continuous regular mining, the overlying rock has formed a caving zone, fracture band, and bending zone (Figure 1). Most of the rock mass structure in the caving zone is loose structure and fragmented structure, with a large residual swelling coefficient and void ratio. The above three moving belts behave obviously in horizontal mining or in gently inclined coal seams. Depending on different roof management methods, goaf size, mining thickness, rock properties, and mining depth, they may not exist simultaneously.

The cavities, separations, and cracks formed in the overlying rock after mining reach a certain compaction and stable state after a long period of physical and mechanical processes. However, the above weak structures cannot be completely eliminated, but they are in a relatively stable state. Instability and deformation will occur when the external force is greater than its resistance $[11,12]$; the goaf is filled with broken rocks, gangue, crushed coal, and waste wood after mining. The mechanical properties of different filling materials are quite different, and the overall stability is poor; there are inevitable pores between the fillings, the middle part of the goaf has better compaction, and there may be larger cavities at both ends, especially the side close to the coal wall. Under the action of water erosion and weathering, the ability of the overall structure to resist external stress decreases.

In addition to the recompaction of residual cracks, the instability of the masonry rock beam structure, and the influence of the geological structure, the activation of the longwall goaf has obvious correlation with mining method, goaf size, and mining depth-thickness ratio. Whether there is a risk of activation in the goaf should be fully considered.

Most goafs are located in a complex geological environment, which determines the diversity of engineering geological conditions. Different types of goafs have different

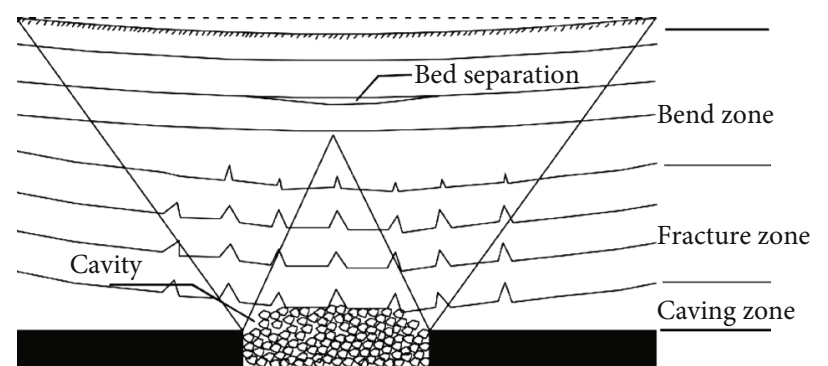

FIgURE 1: Damaged structure model of the overlying rock in the old goaf of the long wall.

engineering geological models. When dividing the engineering geological model of goaf, it is necessary to consider various factors such as mining method and roof management method, topography, geological structure, and final mining time [13-15]; each factor is very important to the stability of goaf. Combining different geological mining conditions and considering the above factors, the engineering geological model can be divided into the following types (Table 1).

From the perspective of engineering construction, the geological condition of stable goafs is relatively simple, the mining area is generally large, and surface movement and deformation are continuous and regular with little residual deformation and little impact on buildings; basically, a stable goaf has a short mining time, and the surface movement has not stabilized, which has a greater impact on ground buildings; an unstable goaf is prone to discontinuous ground deformation, which may have a serious negative impact on ground buildings. Measures such as filling old goafs and controlling ground collapse pits and cracks must be adopted.

\subsection{Development Law of Residual Cavities in Goaf. Effective} grouting reinforcement for the above-mentioned cavities, separation layers, and cracks is the key to successful grouting. It is very important to accurately grasp the location and size of the space, which can be comprehensively determined by combining geophysical and drilling. Theoretically, after the overlying rock strata breaks and collapses and fills the goaf, the uncracked rock strata will bend and sink [16-18]. The effective height of cavities and fissures in the goaf can be regarded as minus the mining thickness. The amount of subsidence and swelling of the collapsed rock mass

$$
m(x)=m-W(x)-h_{p}(x),
$$

where $m(x)$ is the total effective height of the cavity (m), $m$ is the mining thickness $(\mathrm{m}), W(x)$ is the subsidence of the overlying rock $(\mathrm{m})$, and $h_{p}(x)$ is the breaking expansion of the collapsed rock mass $(\mathrm{m})$.

Take the goaf formed by the horizontal coal seam mining where the collapsed rock mass is not full of goaf as an example (Figure 2). Assuming that the elastic foundation supporting the rock beam conforms to the Winkler foundation assumption, the vertical force $R$ in the foundation is

$$
R=k y,
$$


TABLE 1: Classification table of geological mining model of goaf.

\begin{tabular}{lcc}
\hline $\begin{array}{l}\text { Model } \\
\text { type }\end{array}$ & Mode of action & Specific conditions \\
\hline Stable & $\begin{array}{c}\text { Mainly for mining function, longwall mining; reaching or close } \\
\text { to full mining, caving method to manage the roof; more than } \\
\text { 3 years from the final mining time }\end{array}$ & $\begin{array}{c}\text { (1) Depth-thickness ratio } \geq 30 ;(2) \text { topography and stratum are } \\
\text { close to level; (3) there are no faults or penetrating fissures } \\
\text { within the range of mining influence; (4) thickness of loose } \\
\text { ground layer }>10 \mathrm{~m} \text {; (5) ground construction load does not } \\
\text { affect the old goaf area }\end{array}$ \\
\hline
\end{tabular}

Basically Mainly for mining, longwall mining; reaching or close to full stable mining, caving method to manage the roof; 1 to 3 years from the final mining time

(1) Depth-thickness ratio $\geq 30$; (2) terrain level and shallow hills; (3) stratum dip $\leq 45^{\circ}$; (4) no faults or perforated fissures within the range of mining influence; (5) thickness of loose strata $>10 \mathrm{~m}$; (6) the ground construction load has a certain influence on the old goaf

(1) Longwall caving method mining with depth to thickness ratio $<30$; (2) pillar mining; (3) stratum dip $>45^{\circ}$; (4) the ground is mountainous; (5) the strata contains quicksand

Mainly mining, underground mining leads to fault slip and

Unstable mountain slip; large deformed voids remain, which may cause discontinuous deformation of the ground; within 1 year from the final mining time than $10 \mathrm{~m}$; (7) the fault $\operatorname{dip} \delta>30^{\circ}$ and the mining area $S>$ $2000 \mathrm{~m}^{2} ;(8)$ the ground construction load has a large impact on the old goaf

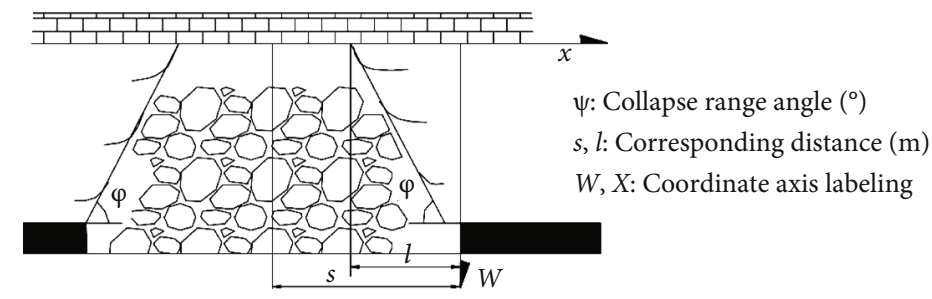

FIGURE 2: Rock mass model of collapsed rock mass not filled with goaf in horizontal coal seam mining.

where $k$ is the Winkler foundation coefficient, which is related to the thickness of the foundation under the beam $(h)$ and the elastic modulus $(E)$ of the overlying rock mass. $k=\sqrt{E / h}$.

Taking the boundary of the goaf as the origin of the abscissa, the differential equation of the deflection curve of the beam can be obtained from the balance principle as

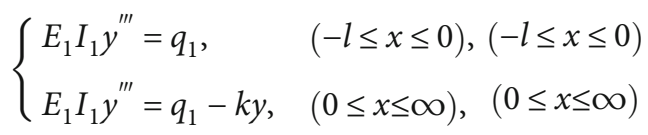

where: $q_{1}$ is the distributed load concentration degree, $q_{1}=E_{1} h_{1}^{3} \sum_{i=1}^{n} \gamma_{i} h_{i} / \sum_{i=1}^{n} E_{i} h_{i}^{3}$.

From the above formula and substituting the relevant boundary and continuity conditions, we can get

$W(x)=\left\{\begin{array}{l}\frac{q_{1}}{E_{1} I_{1}}\left[\frac{1}{24} x^{4}+\frac{1}{6} s x^{3}+\frac{1}{4} s^{2}(1-2 \alpha) x^{2}+\frac{1}{6} s^{3}(1-6 \alpha) x+\left(\frac{\sqrt{2}}{\omega s}+\frac{1}{2}-\alpha\right) \frac{s^{2}}{\omega^{2}}\right], \\ -s<x<0, \\ \frac{q_{1} s^{2}}{E_{1} I_{1} \omega^{2}} e^{-(\omega / \sqrt{2}) x}\left[\left(\frac{\sqrt{2}}{\omega s}+\frac{1}{2}-\alpha\right) \cos \frac{\omega}{\sqrt{2}} x+\left(\alpha-\frac{1}{2}\right) \sin \frac{\omega}{\sqrt{2}} x\right], \\ 0<x<\infty,\end{array}\right.$

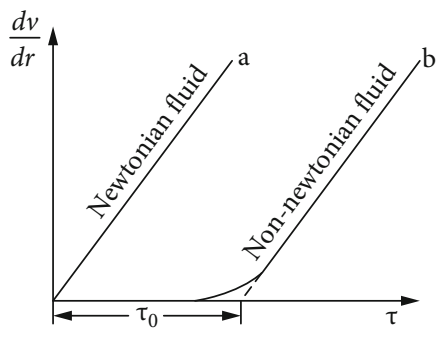

FIGURE 3: Rheological curve of grout.

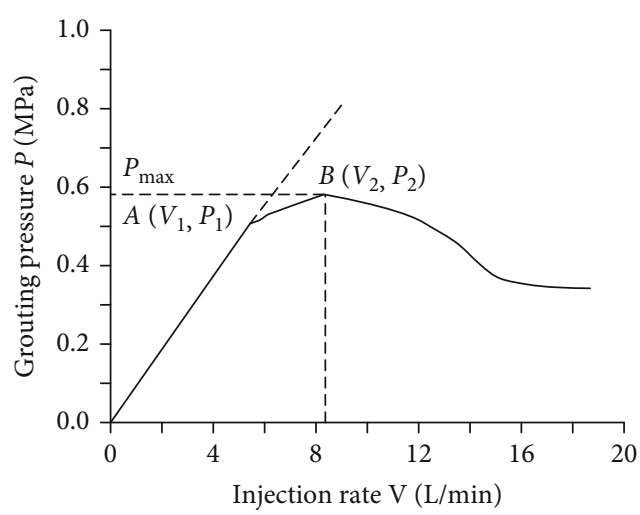

FIGURE 4: Relationship between grouting pressure and grouting speed. 


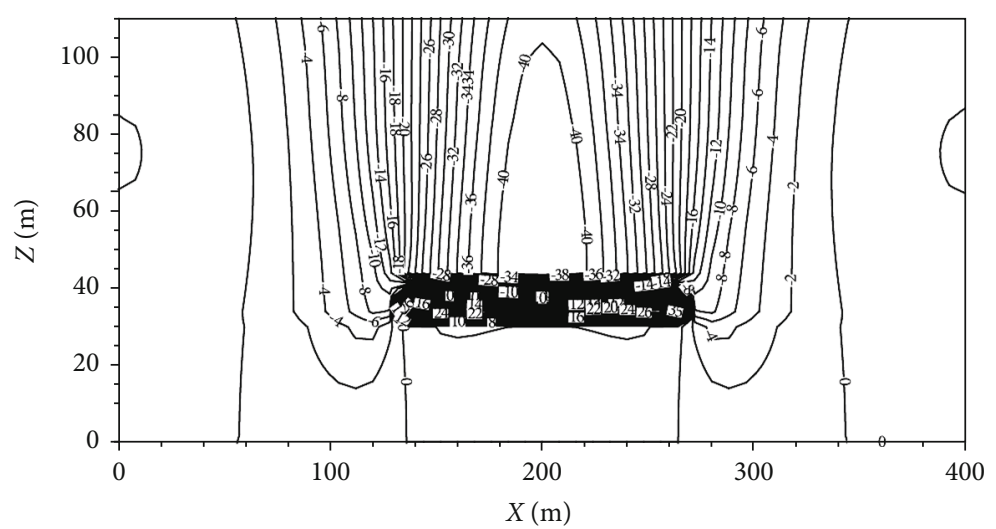

(a) Settlement deformation when the goaf is untreated (mm)

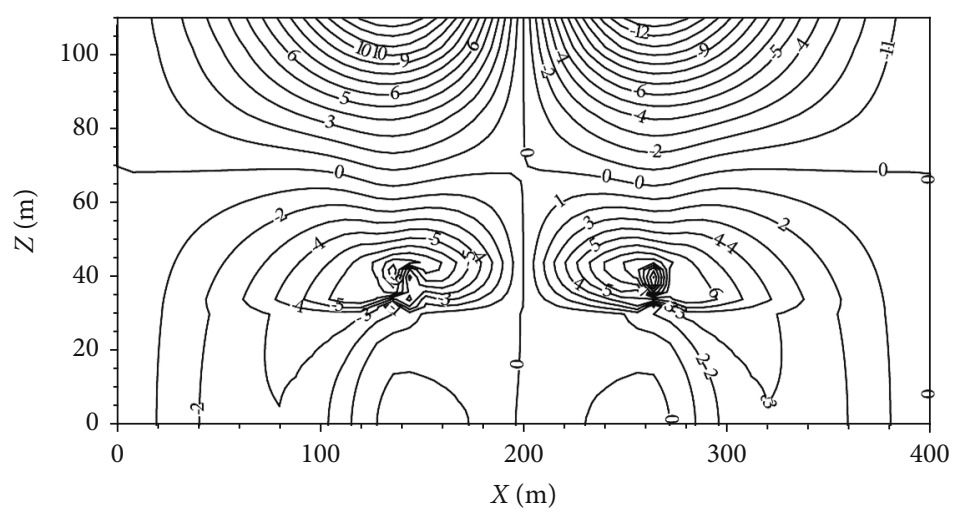

(b) Horizontal displacement change when the goaf is untreated (mm)

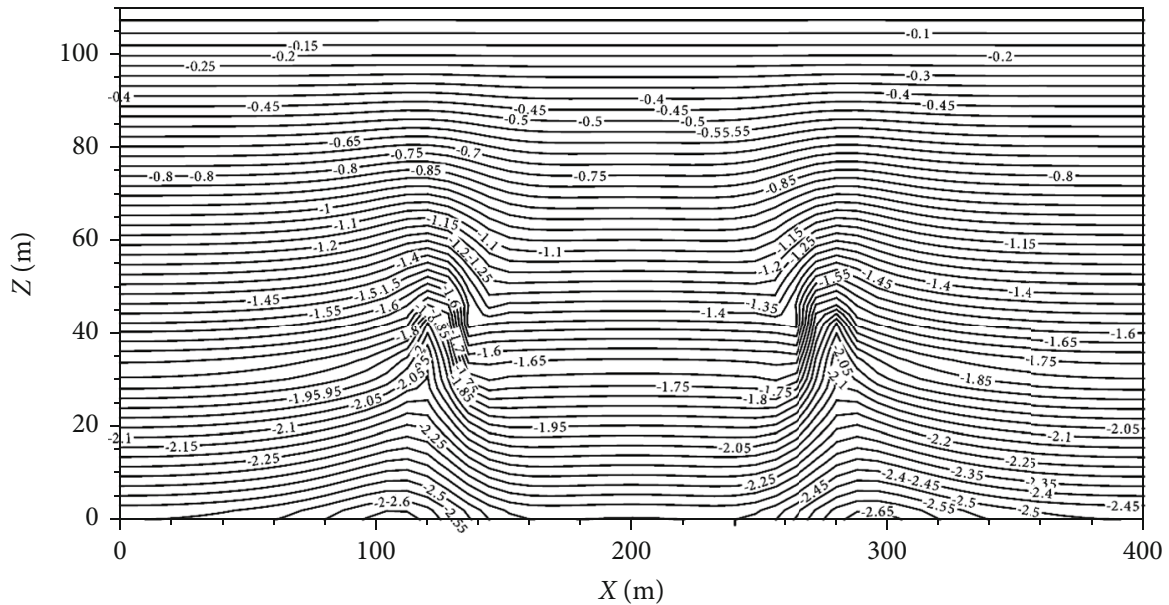

(c) The vertical stress when the goaf is untreated (MPa)

Figure 5: Continued. 


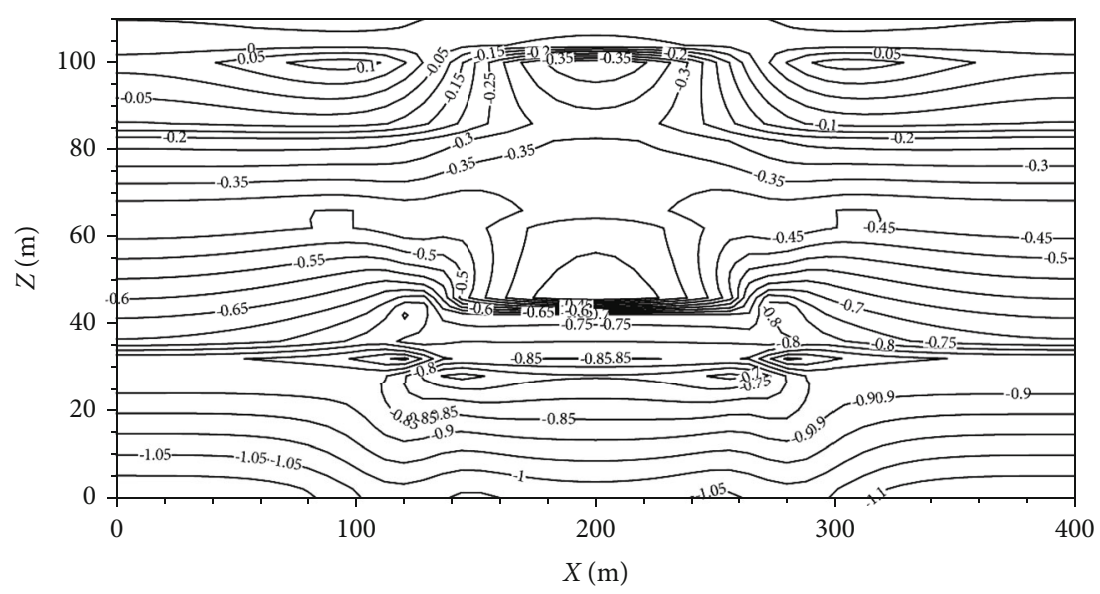

(d) The horizontal stress when the goaf is untreated (MPa)

FIgUre 5: Displacement stress distribution diagram of goaf without grouting.

where $\omega=\sqrt[4]{k / E_{1} I_{1}}$ and $\alpha=\left(\sqrt{2} \omega^{2} s^{2}+6 \omega s+6 \sqrt{2}\right) / 6 \omega s$ $(2+\sqrt{2} \omega s)$.

The total height of old goaf voids formed by horizontal coal seam mining can be obtained from the above formulas as follows:

$$
m(x)= \begin{cases}m-W(x)+(k-1) x \tan \phi, & -l<x<0, \\ m-W(x)-(k-1) l \tan \phi, & -s<x<-l .\end{cases}
$$

It can be seen from the above that the goaf cavity is the largest around the goaf and gradually decreases toward the center, and the mined-out area at the center is the smallest. The largest near the coal pillar, the height of the cavity gradually decreases with the distance from the coal pillar.

\section{Mechanism of Grouting Reinforcement in Goaf}

3.1. Analysis of Grouting Suitability. The "Code for Design of Coal Mine Building Structures" stipulates that it is advisable to use full filling grouting methods for goaf, collapsed area, and mining separation area with large coal mining scale and buried depth of less than $250 \mathrm{~m}$, and according to its mining characteristics, hydrogeology, engineering geological conditions, and its degree of harm to the project, etc., it is necessary to adopt partial filling or full filling grouting schemes for goaf with a buried depth of more than $250 \mathrm{~m}$.

In actual design work, the influencing depth relationship between the falling crack zone and the building load is usually used to determine whether the goaf needs to be treated $[19,20]$. When there is a certain distance or just contact between the impact depth of the building load and the top interface of the collapsed fissure zone, the stability of the collapsed fissure zone will not be affected. It is not necessary to treat goaf, but only to take antideformation measures for the surface buildings or to carry out conservative treatment (local grouting reinforcement) according to the importance of the buildings; when the depth of the building load affects the collapsed fissure zone, it will affect the stability of the collapsed fissure zone, and it must be carried out on the surface of the building. While antideformation is designed, the mined-out area is grouted and reinforced to completely eliminate potential safety hazards.

3.2. Theoretical Analysis of Grouting in Goaf. The purpose of grouting and filling is to make the grout reach the voids, separations, cracks, etc. of the mined-out area and its overlying rock and cement it as a whole [21-23]. The mechanical angle plays a supporting role and improves the self-strength and self-supporting ability of the mined-out area and its overlying rock; the structural angle ensures the stability of the original rock mass structure and avoids sudden instability of the surrounding rock structure system; the pressure angle is slow. The pressure relief allows the surrounding rock to slowly release the pressure, exerting pressure on the surrounding rock, and playing a flexible supporting role for the surrounding rock.

3.2.1. Penetration Theory. The slurry fills the residual space in the goaf under the action of pressure. Through physical and chemical reactions, the slurry forms stones with a certain strength and low water permeability in the pores and cracks, which play a role of reinforcement and antiseepage. At the permeation grouting angle in the goaf, the grout mainly acts on the water-conducting fracture zone and is used for the reinforcement of rock fissures, interrock fissures, and collapsed zone deposits. The grout can be divided into Newtonian fluid and non-Newtonian fluid according to the principle of rheology. The filling material used in the process of grouting treatment in the goaf usually belongs to the Bingham fluid in the non-Newtonian fluid, and its shear rate is not proportional to the shear stress. And only when the yield stress is exceeded can the slurry begin to flow [24-26] (Figure 3).

3.2.2. Split Theory. For the angle of splitting grouting in the mined-out area, the main reinforcement objects are bedrock, residual coal pillars, and residual roadway surrounding rocks. When splitting and grouting the bedrock, the existing 


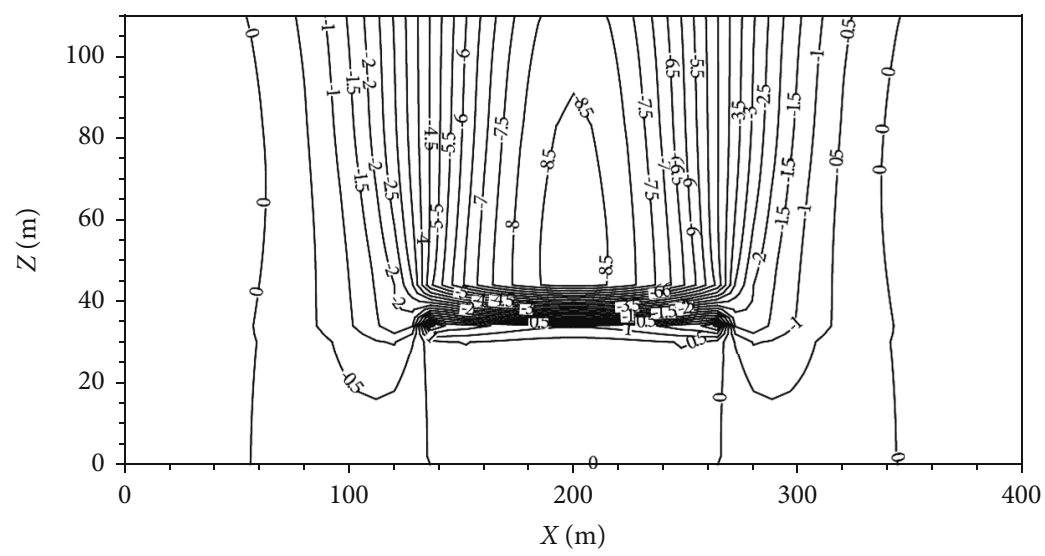

(a) Settlement deformation during full grouting in the goaf ( $\mathrm{mm}$ )

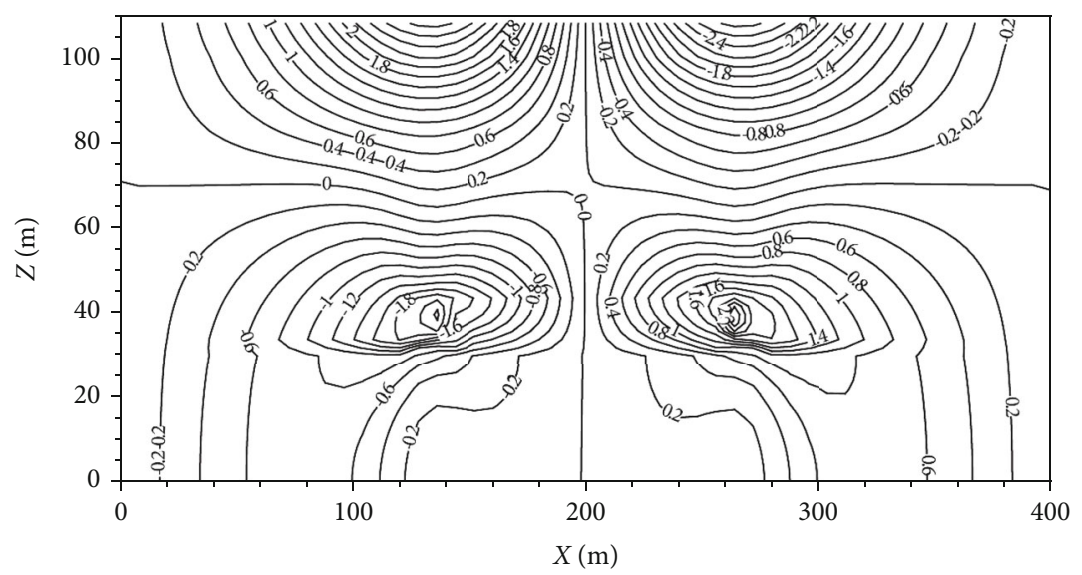

(b) Horizontal displacement change during full grouting in the goaf ( $\mathrm{mm}$ )

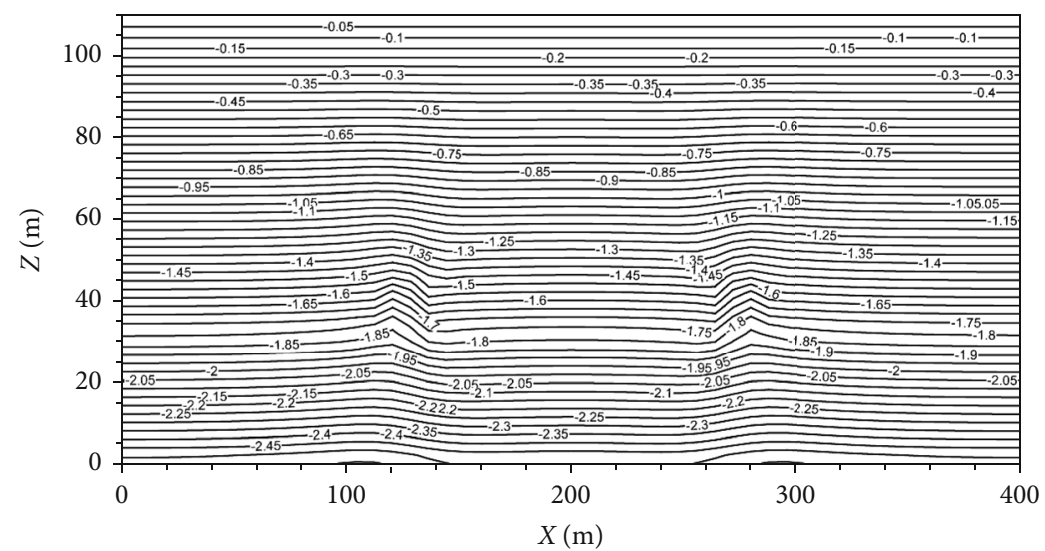

(c) Vertical stress during full grouting in the goaf (MPa)

Figure 6: Continued. 


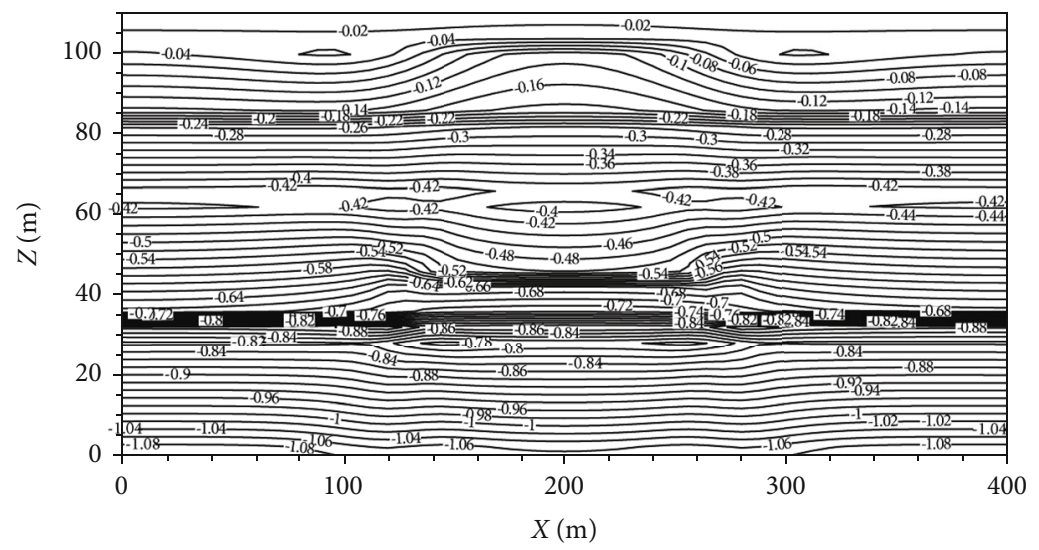

(d) Horizontal stress during full grouting in the goaf ( $\mathrm{MPa})$

FIgURE 6: Displacement stress distribution diagram during full grouting in the goaf.

grouting technology has difficulty in splitting the fresh rock. When splitting the rock formation, the grout often enters the weak zone of the rock formation under pressure to cause splitting. The weak zone is mainly composed of joints and fissures, weak mud, and strong weathered layers [27-29]. On the contrary, when splitting and grouting the coal pillars and the surrounding rock of the remaining roadway, because the coal pillar itself has a low tensile strength, its ability to resist external mechanical action is low, and it is easy to produce a split surface, and the remaining roadway surrounding the rock in splitting surfaces can also be produced on the periphery. To realize split grouting, grouting pressure and grouting speed need to meet certain conditions. The relationship between grouting pressure and grouting speed during grouting is shown in Figure 4.

3.3. Analysis of Grout Reinforcement Mechanism. Fly ash is alkaline, mainly composed of $\mathrm{SiO}_{2}$ and $\mathrm{Al}_{2} \mathrm{O}_{3}$, and contains a small amount of $\mathrm{Fe}_{2} \mathrm{O}_{3}, \mathrm{CaO}, \mathrm{Na}_{2} \mathrm{O}, \mathrm{K}_{2} \mathrm{O}, \mathrm{SiO}_{3}$, etc. The density of fly ash is generally $2.0 \sim 2.5 \mathrm{~g} / \mathrm{cm}^{3}$, and the particle size is $0.5 \sim 300 \mu \mathrm{m}$. The grouting reinforcement mechanism is chemically realized through the hydrolysis and hydration reaction of cement and the pozzolanic reaction of fly ash. Through this series of reactions, the slurry forms a continuous stone body with a certain strength and rigidity, thereby achieving the purpose of filling the cavities, separations, and cracks in the goaf. The chemical reaction formula involved is as follows:

$$
\begin{gathered}
x \mathrm{Ca}(\mathrm{OH})_{2}+\mathrm{SiO}_{2}+m \mathrm{H}_{2} \mathrm{O} \longrightarrow x \mathrm{CaO} \cdot \mathrm{SiO}_{2} \cdot m \mathrm{H}_{2} \mathrm{O} \\
y \mathrm{Ca}(\mathrm{OH})_{2}+\mathrm{Al}_{2} \mathrm{O}_{3}+n \mathrm{H}_{2} \mathrm{O} \longrightarrow y \mathrm{CaO} \cdot \mathrm{Al}_{2} \mathrm{O}_{3} \cdot n \mathrm{H}_{2} \mathrm{O}
\end{gathered}
$$

When cement-clay slurry is used as the filling material, the clay itself undergoes a hydrolysis and ionization reaction before adding cement at the initial stage to form a certain activity and negatively charged clay particles. After adding cement, a series of reactions such as charge exchange and crystallization reaction occur and finally form a gel structure with a certain strength framework. The specific chemical reactions involved are as follows:

$$
\begin{gathered}
3 \mathrm{CaOSiO}_{2}+(n+1) \mathrm{H}_{2} \mathrm{O} \longrightarrow 2 \mathrm{CaO} \cdot \mathrm{SiO}_{2} \cdot \mathrm{H}_{2} \mathrm{O}+\mathrm{Ca}(\mathrm{OH})_{2} \\
\mathrm{SiO}_{2}+\mathrm{Ca}(\mathrm{OH})_{2}+n \mathrm{H}_{2} \mathrm{O} \longrightarrow \mathrm{CaO} \cdot \mathrm{SiO}_{2} \cdot(n+1) \mathrm{H}_{2} \mathrm{O} \\
\mathrm{Al}_{2} \mathrm{O}_{3}+\mathrm{Ca}(\mathrm{OH})_{2}+n \mathrm{H}_{2} \mathrm{O} \longrightarrow \mathrm{CaO}\left(\mathrm{Al}_{2} \mathrm{O}_{3}\right) \cdot(n+1) \mathrm{H}_{2} \mathrm{O}
\end{gathered}
$$

Through the above-mentioned physical and chemical reactions; the formation of grout stones is promoted; cracks, separations, and collapse zones in the mined-out area are filled and reinforced; and the purpose of effective reinforcement is finally achieved.

\section{Numerical Simulation Analysis of Grouting Reinforcement in Goaf}

4.1. Establishment of Grouting Reinforcement Model. According to theoretical analysis and field experience, under normal circumstances, whole grouting is a method of mixing filling materials in a certain proportion into the whole mined-out area and overlying rock cracks and separation layers to completely eliminate potential safety hazards; it is suitable for goaf areas, subsidence areas, and mining separation areas with a large coal seam mining scale and a buried depth of less than $250 \mathrm{~m}$. Local grouting in the fracture zone is a method to recement the fractured rock blocks in the fracture zone into a layered whole, thereby improving the stability and bearing capacity of the overlying rock. It is suitable for reinforcing the situation where there are cavities or cracks on the boundary of the goaf. Strip grouting is a method of supporting the overlying rock mass together with the rock mass and the fractured rock mass under the premise that the strength of the grouted rock mass is sufficient to resist damage and the rigidity is sufficient to resist deformation; it is suitable for the case where the load transmission depth of the building does not touch the critical height of the water-conducting fissure zone. In this simulation, two situations of whole grouting and strip grouting are simulated and analyzed.

The model is based on the geological mining conditions of a subsidence area in Xingtai city, Hebei Province, China. Study area is generalized as a plane strain model along the coal seam incline. The model is $400 \mathrm{~m}$ long, $1 \mathrm{~m}$ wide, and 


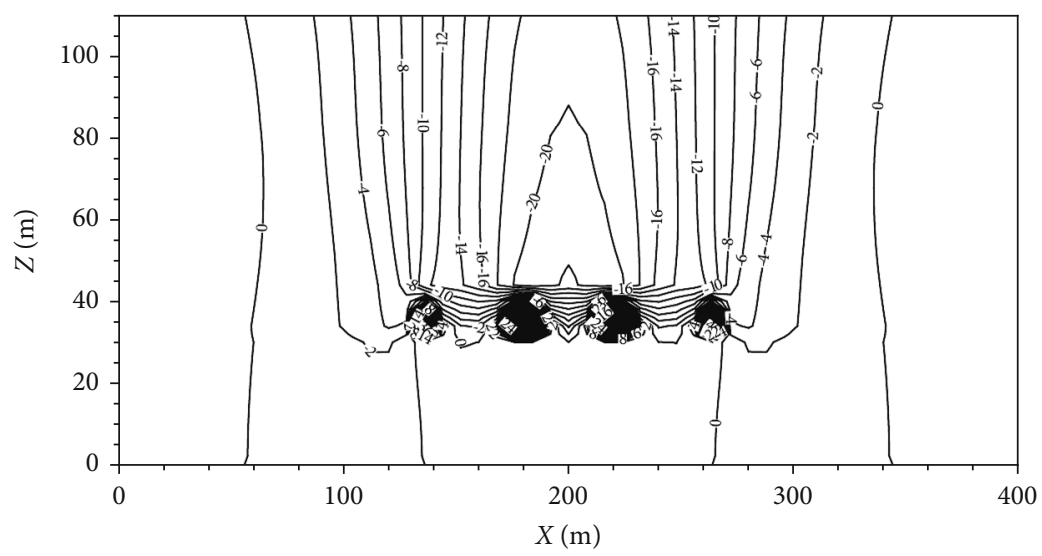

(a) Settlement deformation during strip grouting in the goaf ( $\mathrm{mm}$ )

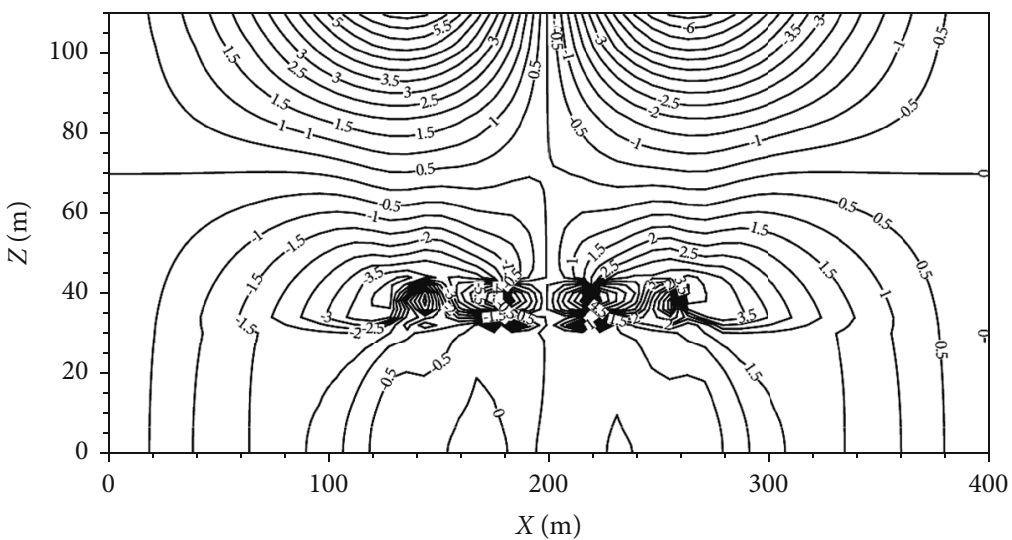

(b) Horizontal displacement change during strip grouting in the goaf (mm)

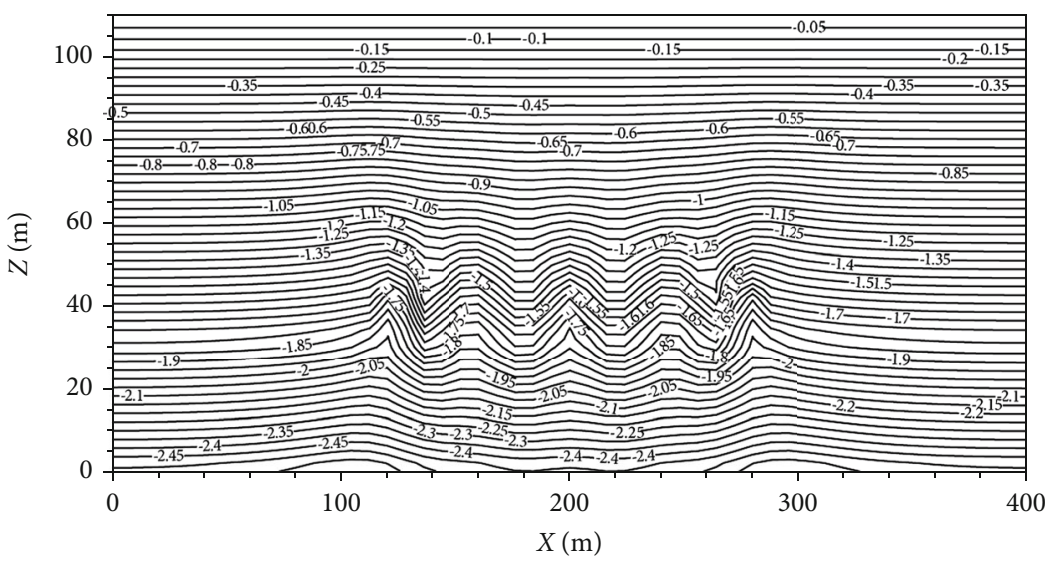

(c) Vertical stress during strip grouting in the goaf $(\mathrm{MPa})$

Figure 7: Continued. 


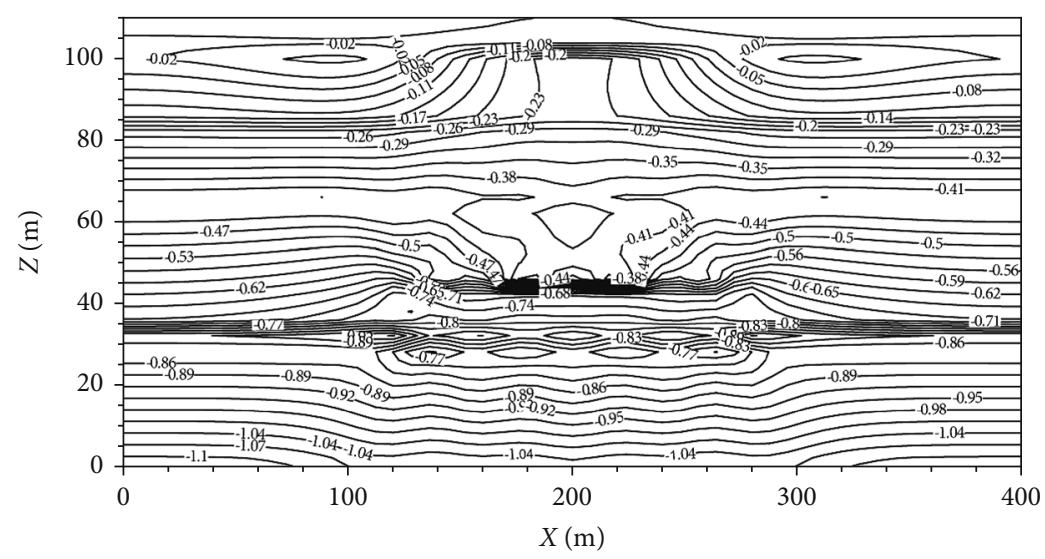

(d) Horizontal stress during strip grouting in the goaf $(\mathrm{MPa})$

FIgURe 7: Displacement stress distribution diagram during strip grouting in the goaf.

TABLE 2: Observation of the depth statistics of borehole fracture development.

\begin{tabular}{lccc}
\hline $\begin{array}{l}\text { Drilling serial } \\
\text { number }\end{array}$ & Depth of fissure development $(\mathrm{m})$ & $\begin{array}{c}\text { Detection depth } \\
\text { (m) }\end{array}$ & $\begin{array}{c}\text { Proportion of } \\
\text { fissure }(\%)\end{array}$ \\
\hline 4 & $31.0 \sim 38.5,65.5 \sim 74.5,128.5 \sim 130,157.7 \sim 159.2,162.2 \sim 163.7,187.7 \sim 197.7$, & $28.0 \sim 245.4$ \\
& $234.2 \sim 237.2$ & 15.6 \\
8 & $40.5 \sim 45,52.5 \sim 57,64.5 \sim 70.5,96 \sim 97.5,100.5 \sim 102.0,167.1 \sim 168.6,170.1 \sim 177.6$, & $40.5 \sim 230.0$ \\
& $191.1 \sim 200.1$ & 19.0 \\
18 & $85.4 \sim 88.4,89.9 \sim 92.9,95.7 \sim 100.7,113.7 \sim 116.7,122.7 \sim 125.0,128.7 \sim 134.7$, & $85.4 \sim 193$ \\
& $142.7 \sim 149.7,169.7 \sim 175.7$ & 32.8 \\
\hline
\end{tabular}

$110 \mathrm{~m}$ high, divided into $50 \times 1 \times 55$ units. In the model, coal thickness is $4 \mathrm{~m}$, mining depth is $76 \mathrm{~m}$, and mining area is $125 \mathrm{~m} \sim 275 \mathrm{~m}$, which has reached full mining. According to the calculation of the "three under" mining regulations, it can be seen that the heights of the caving zone and waterconducting fissure zone are about $10 \mathrm{~m}$ and $50 \mathrm{~m}$, respectively.

This simulation generalized the model into a horizontal layered structure, with 6 layers of siltstone, coal, sandstone, and argillaceous sandstone from bottom to top. During the simulation process, the final results are mainly analyzed from the perspective of displacement and stress. The dynamic flow process of the slurry is not considered.

\subsection{Simulation Method Selection and Process Determination.} In order to better analyze the grouting effect under each model condition, FLAC3D software is used to simulate the grouting reinforcement effect from multiple angles such as displacement and stress. The Mohr-Coulomb model is selected as a constitutive model due to need to consideration of loose media such as topsoil, rock, coal seams, and cemented granular media. The main parameters include elastic bulk modulus, cohesion, dilatancy angle, internal friction angle, elastic shear modulus, and tensile strength. In the simulation process, the collected physical and mechanical parameters of grouting stone bodies from previous projects are compared and corrected, and the physical and mechanical parameters of the grouted stone bodies are finally determined. On this basis, the determined collapse zone, fracture zone, and separation zone are given "strengthening" treatment to obtain the settlement, horizontal movement, and force condition after grouting. In terms of postprocessing, FLAC3D has powerful postprocessing capabilities. The results can be displayed in the form of cloud diagrams, vector diagrams, curves, data, animations, etc. However, some professional calculation results cannot be directly obtained and need to combine with the embedded FISH language programming or with the help of other software. According to the actual situation, combined with tecplot software and Surfer software, the simulation results are postprocessed [30-32].

4.3. Analysis of Calculation Results. After the initial model without grouting reaches a stable state (Figure 5), the maximum residual subsidence value of the ground surface is $43 \mathrm{~mm}$, the residual subsidence coefficient is about 0.011 , and the maximum subsidence value is located directly above the goaf, which is mainly due to further compaction of the rock mass in the goaf and caving zone and the closure of the separated layer and gap in the fracture zone; horizontal movement is mainly concentrated on both sides of goaf and the surface above the goaf. The maximum movement value on both sides of the goaf is $14 \mathrm{~mm}$, which is mainly when the following phenomenon occurs, when the changing trend is gradually decreasing from above the goaf boundary to above the center of goaf, and the horizontal movement value 


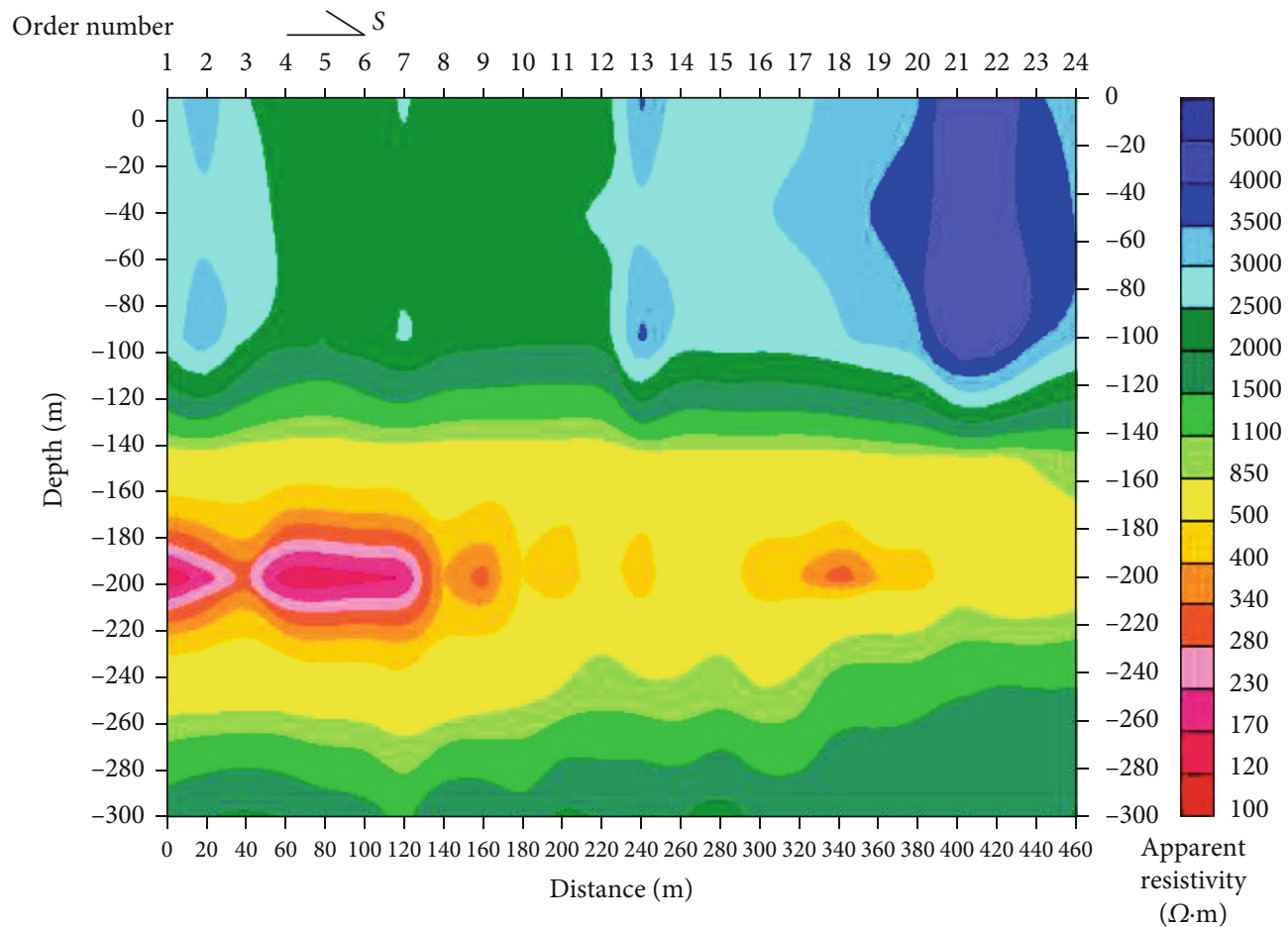

(a) Before grouting

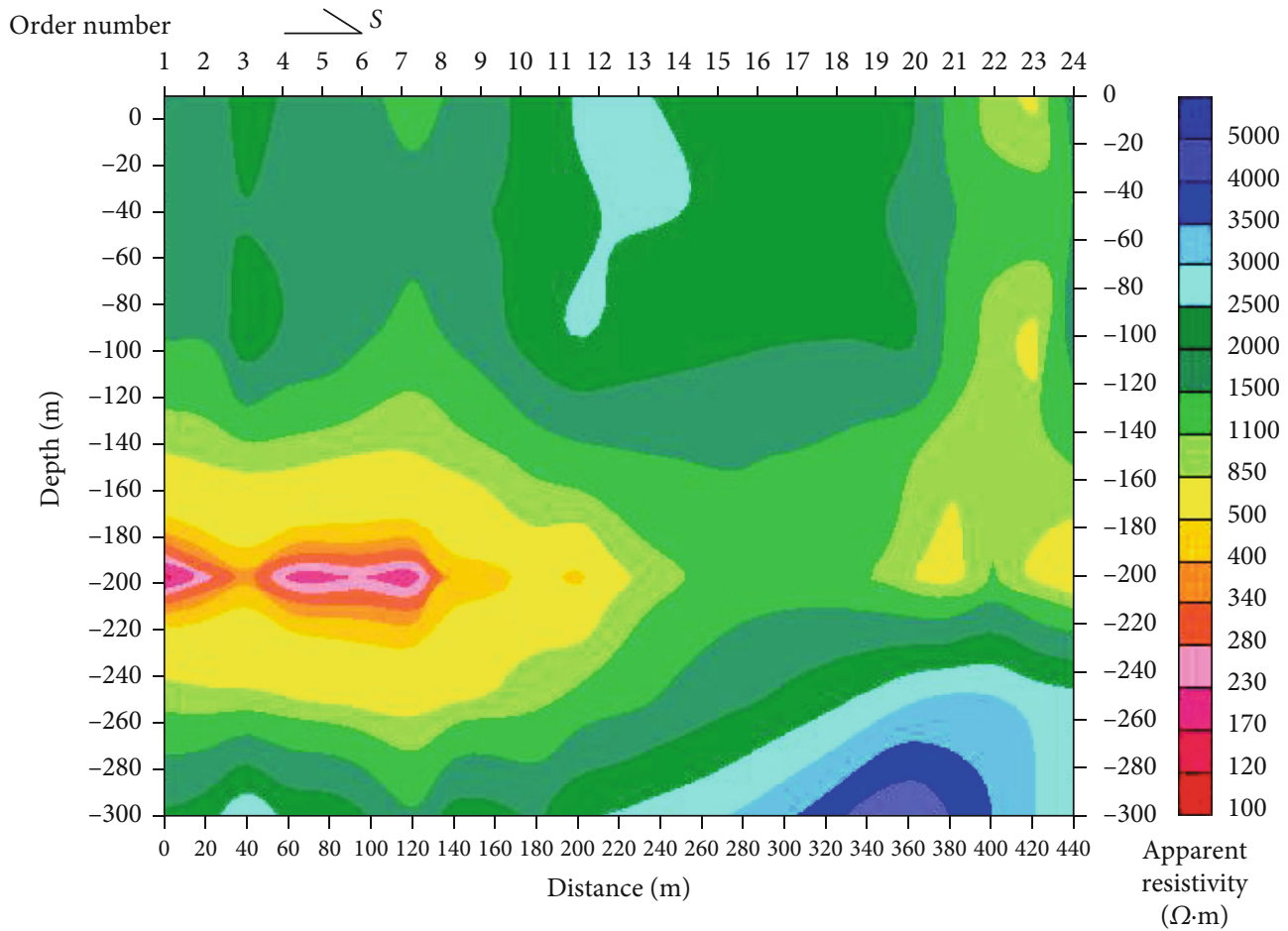

(b) After grouting

FIgURE 8: Resistivity profile of the cooling tower area.

above the center of the goaf is zero. The change trend of vertical stress and horizontal stress corresponds to settlement deformation and horizontal displacement.

After whole grouting treatments (Figure 6), the maximum residual subsidence of the ground surface is reduced from $43 \mathrm{~mm}$ before grouting to $9 \mathrm{~mm}$, and the horizontal movement value is reduced from $13 \mathrm{~mm}$ before grouting to $3 \mathrm{~mm}$. The subsidence of the ground surface mainly comes from the consolidation and deformation of the loose layer on the ground. The distribution of vertical stress and horizontal stress around the goaf is more uniform than before reinforcement, and the numerical value is greatly reduced. 


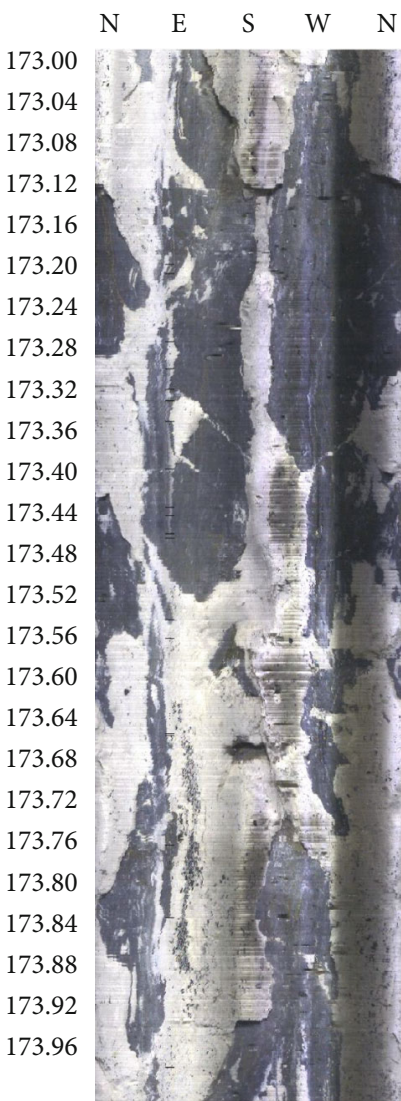

(a) Depth 173.0 174.0 m

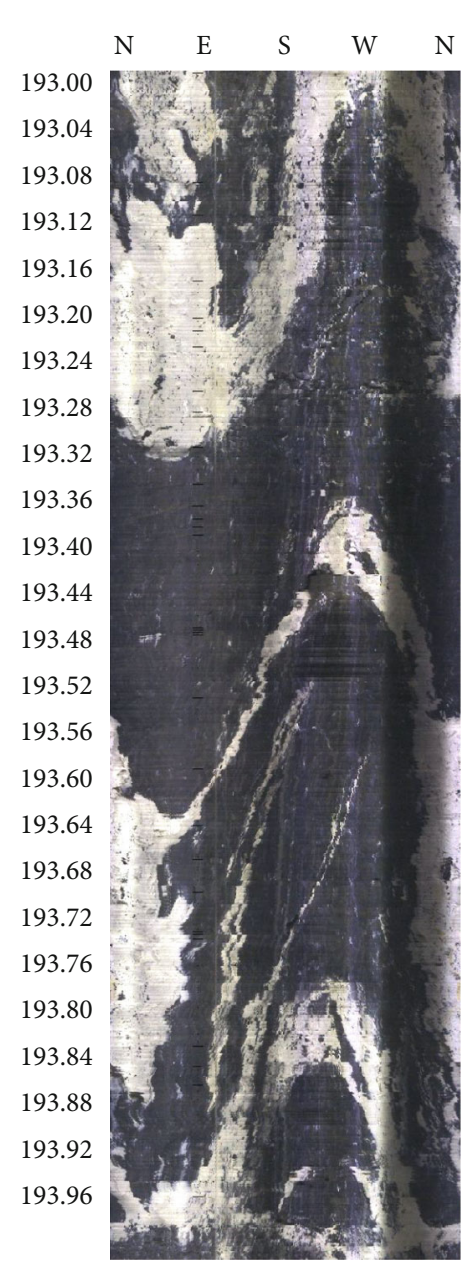

(b) Depth 193.0 194.0 m

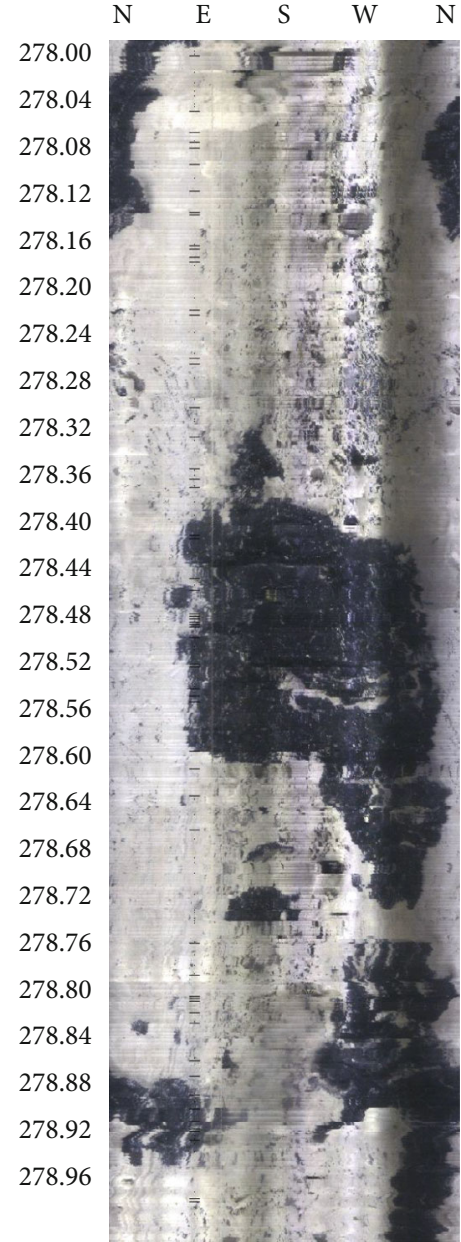

(c) Depth 278.0 279.0 m

Figure 9: Filling situation of rock formation cracks below $170 \mathrm{~m}$ in No. II inspection hole.

After the strip grouting treatment in the goaf (Figure 7), the maximum surface subsidence is about $21 \mathrm{~mm}$, which is between $43 \mathrm{~mm}$ before grouting and $9 \mathrm{~mm}$ after grouting. The vertical stress and horizontal stress are compared to the overall distribution before grouting. Although there is a stress concentration phenomenon at the edge of the beltshaped filling body, the force on the edge of the coal pillar that is mined before the grouting is relatively small in value. The whole goaf is relatively stable, and the ability to resist interference from external force is much stronger than that without grouting.

\section{Engineering Example}

This study takes the construction site of the third phase of the Kailuan Tangjiazhuang Thermal Power Plant as an engineering example, which is located in the Guye District, Tangshan City, Hebei Province, China. Comprehensive analysis of drilling construction records and actual drilling data (Table 2) are used to determine that overlying rock in the goaf is affected by multiple seam mining. Although compacted for decades, its stability is still poor. The range of damage and fracture development in rock exceeds the original estimate. Under the disturbance of surface load and other factors, secondary deformation may occur in the goaf and unstable rock mass above it. It is necessary to deal with unstable rock formations in the goaf under important buildings to ensure the safe operation of thermal power plants.

The grouting holes are arranged in multiple staggered rows, and the design hole distance is $50 \mathrm{~m}$. Three rows of grouting holes are arranged on the annular foundation of the cooling tower (a total of 13 grouting holes); the main plant area is also arranged with three rows of 13 grouting holes, and the actual treatment area is about $51,000 \mathrm{~m}^{2}$. Considering the destruction of the overlying rock strata in the goaf, the treatment project adopts the step-down grouting filling method.

A total of 3 north-south detection lines were set up according to the arrangement direction, location, and rock formation tendency of the grouting boreholes After the goaf was treated by grouting, the apparent resistivity values of three survey lines are higher than those before grouting (Figure 8); the apparent resistivity profile basically disappeared or the range was obviously reduced after treatment (Figure 9), which indicated that the integrity and uniformity of rock mass in the goaf have been improved after grouting 
treatment, increasing the bearing capacity of the formation. Most areas have reached the treatment requirements, and additional grouting was carried out in time for some unfilled dense areas and finally achieved the expected goal of grouting treatment which was verified with inspection holes.

Since the construction and operation of the third phase of the thermal power plant, the relevant buildings (structures) have not shown obvious deformation and damage, and the operation is in good condition.

\section{Conclusion}

(1) The goaf left by longwall mining has its unique complexity, and the damage status of the overlying rock layer is difficult to accurately predict and master, which brings great safety hazards to the project construction. When carrying out engineering construction above the goaf, the influence of residual deformation must be considered. On the basis of reasonable detection and scientific evaluation, necessary measures such as underground grouting reinforcement and surface construction antideformation shall be taken as needed

(2) Numerical simulation reveals the changes in settlement deformation and horizontal movement of the goaf and its overlying rock before and after grouting under different grouting treatment conditions, as well as the distribution of vertical and horizontal stresses. The simulation results show that the whole grouting effect is the best, which can meet treatment requirements to the greatest extent; the strip grouting can also serve the purpose of reinforcing the goaf to a certain extent, and it can also be an effective method for goaf treatment under certain conditions

(3) Grouting reinforcement is one of the effective methods to deal with the residual deformation of the goaf. There are still some shortcomings in the reinforcement mechanism and technical methods. This study only analyzed the effect before and after grouting and did not conduct real-time research on the whole process of dynamic grouting, which needs further research

\section{Data Availability}

The experimental data used to support the findings of this study are included within the article.

\section{Conflicts of Interest}

The authors declare no conflict of interest.

\section{Acknowledgments}

This research was funded by the Beijing Science and Technology Planning Project (Z181100005118012) and China Coal Science and Industry Group Science and Technology Innovation Venture Capital Special Key Project (2018-2-ZD007).

\section{References}

[1] Z. Yang, Y. Q. Lv, and G. K. Sun, "Influence of multi-coal goaf on stability of upper proposed building," Journal of Xi'an University of Science and Technology, vol. 40, no. 5, pp. 862-868, 2020.

[2] Z. X. Liu, C. X. Wang, L. L. Yang, Q. C. Sun, and N. Jiang, "Simulation analysis of key factors of activation instability in goaf," Safety in Coal Mines, vol. 50, no. 6, pp. 240-244, 2019.

[3] G. L. Guo, K. Z. Deng, H. Y. Wang, Z. A. Huang, and S. J. Chen, "Research on the mechanism of foundation instability above the mined-out area and treatment measures," Mine pressure and roof management, vol. 17, no. 3, pp. 39-42, 2000.

[4] K. Z. Deng, Z. X. Tan, and H. Z. Zhang, "Design method of strip grouting for old longwall mining goaf," Journal of China Coal Society, vol. 33, no. 2, pp. 153-156, 2008.

[5] D. X. Xuan, G. L. Hu, W. B. Zhu, and L. Wang, "Field test on dynamic disaster control by grouting below extremely thick igneous rock," Journal of China Coal Society, vol. 37, no. 12, pp. 1967-1974, 2012.

[6] Y. Z. Pang, C. Y. Liu, L. M. Zuo, X. H. Zhao, and Y. F. Liu, "Experimental study on preparation and properties of new grouting material for goaf filling," Bulletin of The Chinese Ceramic Society, vol. 36, no. 7, pp. 2268-2274, 2017.

[7] X. L. Wang, Q. S. Wang, Z. Y. Zhou, and X. F. Ao, “Threedimensional turbulent numerical simulation of Bingham fluid in the goaf grouting of the South-to-North water transfer project," Journal of Hydraulic Engineering, vol. 44, no. 11, pp. 1295-1302, 2013.

[8] X. L. Li, L. G. Wang, N. Zhao, and Z. Hao, "Experimental research on mixing ratio of grouting material for goaf under railway," Bulletin of The Chinese Ceramic Society, vol. 33, no. 3, pp. 651-655, 2014.

[9] Z. Lu, K. Z. Deng, and Y. Q. Jin, "Determination of grouting filling area in goaf with longwall mining," Journal of Mining and Safety Engineering, vol. 25, no. 4, pp. 499-501, 2008.

[10] P. E. Yongliang, H. U. Xiewen, S. O. Dage, and H. E. Xin, "Inspection method for grouting effect in treating large complicated cavities due to mining," Journal of Engineering Geology, vol. 21, no. 4, pp. 664-671, 2013.

[11] G. R. Feng, J. W Bai, X. D. Shi et al., "Key pillar theory in the chain failure of residual coal pillars and its application prospect," Journal of China Coal Society, vol. 46, no. 1, pp. 164179, 2021.

[12] D. H. Wang, W. Li, and B. Zhang, "Present situation and prospect of research on prevention and control technologies of coal mine goaf instability disaster," Safety in Coal Mines, vol. 51, no. 3, pp. 188-193, 2020.

[13] J. Zhang and B. Wang, "Stability of isolated coal pillar and overburden instability in shallow-buried interval gob," Journal of Mining \& Safety Engineering, vol. 37, no. 5, pp. 936-942, 2020.

[14] Y. Wang, Y. F. Yi, C. H. Li, and J. Q. Han, “Anisotropic fracture and energy characteristics of a Tibet marble exposed to multi-level constant-amplitude (MLCA) cyclic loads: a labscale testing," Engineering fracture mechanics, vol. 244, article 107550, 2021.

[15] X. B. Xie, R. N. Deng, X. J. Dong et al., "Stability of goaf group system based on catastrophe theory and rheological theory," Rock and Soil Mechanics, vol. 39, no. 6, pp. 19631972, 2018. 
[16] Y. Wang, C. H. Li, H. Liu, and J. Q. Han, "Fracture failure analysis of freeze-thawed granite containing natural fracture under uniaxial multi-level cyclic loads," Theoretical and Applied Fracture Mechanics, vol. 110, article 102782, 2020.

[17] H. Z. Zhang, K. Z. Deng, and W. Gu, "Distribution law of the old goaf residual cavity and void," Journal of Mining \& Safety Engineering, vol. 33, no. 5, pp. 893-897, 2016.

[18] G. L. Bai, S. Z. Li, and J. H. Gao, "Crack development characteristic of rock strata over abandoned gob and its activation mechanism," Coal Mining Technology, vol. 15, no. 5, p. 11, 2010.

[19] Q. Xv, W. Zhu, H. Y. Teng, and Z. X. Tang, "Study on the construction technique of large-scale factory building above coal mining subsidence area," Metal Mine, vol. 54, no. 10, pp. 153-157, 2019.

[20] Y. H. Teng and J. Y. Zhang, "Evaluation on stability of building foundation over goafs," Journal of China Coal Society, vol. 34, no. 5, pp. 58-62, 1997.

[21] Z. P. Zhang, F. Li, and H. C. Zhang, "Stability analysis and evaluation of grouting treatment effect on goaf of steeply inclined thick coal seam," Science Technology and Engineering, vol. 21, no. 4, pp. 1312-1317, 2021.

[22] W. J. Zhang and Y. Guo, "Study on grouting filling construction method of goaf in mountain area," Modern Tunnelling Technology, vol. 57, no. S1, pp. 1182-1186, 2020.

[23] X. L. Li, S. Z. Li, and F. M. Li, "Research on grouting consolidation of foundation over abandoned mine goaf," Metal Mine, vol. 46, no. 11, pp. 33-36, 2011.

[24] Q. S. Zhang, H. B. Wang, R. T. Liu et al., "Infiltration grouting mechanism of porous media considering diffusion paths of grout," Chinese Journal of Geotechnical Engineering, vol. 40, no. 5, pp. 918-924, 2018.

[25] Y. A. Zhi-quan, H. O. Ke-peng, and W. Liang, "Study of diffusion parameters of Newtonian fluid based on columnhemispherical penetration grouting," Rock and Soil Mechanics, vol. 35, no. S2, pp. 17-24, 2014.

[26] Y. Wang, C. H. Li, and J. Q. Han, "On the effect of stress amplitude on fracture and energy evolution of pre-flawed granite under uniaxial increasing-amplitude fatigue loads," Engineering Fracture Mechanics, vol. 240, p. 107366, 2020.

[27] M. R. Zhou, G. W. Lu, T. Wang, and W. A. Jin-wei, "Mechanism analysis of structural loess fracturing grouting," Engineering mechanics, vol. 36, no. 3, pp. 169-181, 2019.

[28] Z. Y. Song, Y. Wang, H. Konietzky, and X. Cai, "Mechanical behavior of marble exposed to freeze-thaw-fatigue loading," International Journal of Rock Mechanics and Mining Sciences, vol. 138, article 104648, 2021.

[29] M. T. Zhu, Q. S. Zhang, S. C. Li, R. T. Liu, and L. Z. Zhang, "Numerical simulation and experimental study on soil split grouting reinforcement mechanism," Journal of Central South University, vol. 49, no. 5, pp. 1213-1220, 2018.

[30] X. L. Li, "Numerical simulation method analysis for goaf problem," Safety in Coal Mines, vol. 43, no. 12, pp. 193-196, 2012.

[31] H. W. Zhu, H. L. Zhu, K. P. Zhou, and X. Xiao, "Study on optimization of pre-processing and post-processing for numerical simulation based on FLAC3D," Mining R\&D, vol. 28, no. 2, pp. 60-62, 2008.

[32] X. L. Li, F. M. Li, and F. Zhou, "Band type grouting reinforcement mechanism and numerical analysis," Coal Engineering, vol. 59, no. 11, pp. 85-88, 2012. 